\section{Produtos de hidratação em argamassas geopoliméricas à base de argila da Tunísia para reparação de estruturas de concreto}

\author{
Hydration products of geopolymeric \\ mortars based on Tunisian clay for \\ repair of concrete structures
}

\author{
Walid Tahri ${ }^{1}$, Basma Samet ${ }^{1}$, Fernando Pacheco-Torgal ${ }^{2,3}$ \\ José Aguiar $^{2}$, Samir Baklouti ${ }^{1}$
}

\author{
${ }^{1}$ University of Sfax, Sfax, Tunisia \\ e-mail: walidtahri1980@yahoo.fr; sametbasma@yahoo.fr; baklouti.samir@gmail.com \\ ${ }^{2}$ C-TAC, Universidade do Minho, Guimarães, Portugal \\ ${ }^{3}$ SHRC, Universidade de Sungkyunkwan, Suwon, Coreia do Sul \\ e-mail: torgal@civil.uminho.pt; aguiar@civil.uminho.pt
}

\section{RESUMO}

A reparação de estruturas degradadas de concreto representa uma oportunidade para a indústria da construção mas também um desafio para a comunidade científica. $\mathrm{O}$ desenvolvimento de novas argamassas de reparação constitui por isso uma importante área de investigação. Os geopolímeros são ligantes inovadores alternativos ao cimento Portland pelo que as argamassas à base destes materiais, geopolíméricas, apresentam algumas potencialidades no campo da reparação das estruturas de concreto.

O presente artigo apresenta resultados de uma investigação sobre o desenvolvimento de argamassas geopoliméricas à base de uma argila da Tunísia sujeita a tratamento térmico. É incluída uma análise da argila e também dos produtos de hidratação da argamassa os quais apresentam fases geopoliméricas típicas.

Palavras-chave: Estruturas de concreto, argamassas de reparação, geopolímeros, argila calcinada, metacaulim

\section{ABSTRACT}

The rehabilitation of concrete structures represents an opportunity for the construction industry as well as a challenge for the scientific community. The development of new repair mortars is thus an important research area. Gopolymers are innovative binders alternative to Portland cement being that the geopolymeric mortars present some advantages concerning the repair of concrete structures.

This paper presents investigations results regarding the development of gepolymeric mortars based on a calcined Tunisian clay. A characterization of the clay is included as well as of the mortars hydration products that show typical geopolymeric phases.

Keywords: Concrete structures, repair mortars, geopolymers, calcined clay, metakaolin

\section{INTRODUÇÃO}

Os custos associados à reabilitação de estruturas de concreto a nível mundial apresentam valores astronómicos. Alguns autores [1] referem que só nos Estados Unidos são necessários mais de 1.6 triliões de dólares para obras de reparação destas estruturas. Parte do problema está relacionado com o facto dessas estruturas terem sido construídas quando inexistiam preocupações sobre a durabilidade nem sequer mesmo um conhecimento científico sólido sobre este tema [2].

Materiais com baixa durabilidade necessitam de frequentes operações de manutenção e conservação ou mesmo a sua substituição integral o que implica o consumo de matérias-primas e energia com evidente 
impacto ambiental.

A maioria das operações de reabilitação de estruturas de concreto é feita com recurso à utilização de argamassas de reparação localizadas [3,4]. As argamassas de reparação subdivide-se em duas categorias principais, as argamassas à base de cimento Portland e as argamassas à base de polímeros orgânicos (resinas epoxy ou poliéster). As primeiras estão associadas a elevadas emissões de dióxido de carbono [5] enquanto as últimas são conhecidas por terem algum tipo de toxicidade [6].

Os geopolímeros são ligantes inovadores alternativos ao cimento Portland [7]. A geopolimerização de alumino-silicatos é um processo químico complexo que envolve a dissolução das matérias-primas, o transporte, orientação e policondensação dos produtos de reacção [8-11].

As investigações no domínio dos geopolímeros revelam uma terceira família de argamassas com capacidade para serem utilizadas na reparação localizada de estruturas de concreto [12]. Alguns autores [13] mostraram que provetes de concreto reparados com argamassas geopoliméricas apresentavam ao fim de apenas um dia de cura uma aderência superior à de provetes de concreto, reparados com argamassas comerciais, mesmo depois de 28 dias de cura. Trata-se de um desempenho muito promissor pois a aderência da argamassa de reparação ao concreto do substrato é uma propriedade muito importante para se obter uma boa reparação [14].

Este artigo apresenta resultados relativos ao desenvolvimento de uma argamassa geopolimérica para reparação de concreto à base de uma argila da Tunísia.

\section{MATERIAIS E MÉTODOS}

\subsection{Materiais}

A argila utilizada na presente investigação é proveniente da região de Medenine na Tunisia. A sua composição quimica é apresentada na Tabela 1.

Tabela 1: Composição química da argila

\begin{tabular}{|c|c|c|c|c|c|c|c|c|}
\hline $\mathrm{SiO}_{2}$ & $\mathrm{Al}_{2} \mathrm{O}_{3}$ & $\mathrm{Fe}_{2} \mathrm{O}_{3}$ & $\mathrm{CaO}$ & $\mathrm{MgO}$ & $\mathrm{SO}_{3}$ & $\mathrm{~K}_{2} \mathrm{O}$ & $\mathrm{Na}_{2} \mathrm{O}$ & $\mathrm{PF}$ \\
\hline 60,8 & 12,6 & 5,87 & 2,15 & 2,38 & 0,08 & 2,71 & 0,003 & 9,7 \\
\hline
\end{tabular}

A argila foi sujeita a moagem e peneirada atrás de peneiro com malha de $100 \mu \mathrm{m}$ posteriormente foi submetida a tratamento térmico em forno elétrico (Nabertherm, Mod.LH 60/14) durante 6 h com uma taxa de aquecimento de $11,33^{\circ} \mathrm{C} / \mathrm{min}$ até $700{ }^{\circ} \mathrm{C}$. A Figura 1 apresenta os espectros de difração de raio-X da argila os quais confirmam que a mesma é constituída por caulinita e quartzo. Na mesma notam-se também picos de ilita $\left(8,8^{\circ}\right)$.

Na Figura 1 constata-se o desaparecimento de picos de caulinita e a sua transformação em metacaulinita. Constata-se uma redução da cristalinidade dos picos deste mineral que é característica da transição do mesmo para um estado mais desordenado (amorfo). Os picos de ilita mantém-se quase intactos comprovativos de uma calcinação incompleta. Por outro lado a calcinação da gibbsita leva à sua transformação em $\mathrm{CaSO}_{4}$.

A Figura 2 apresenta as curvas de Análise Térmica Diferencial e Termogravimétrica (ATD/TG) da argila que são típicas de argilas contendo caulinita $[15,16]$. $\mathrm{O}$ intervalo $\left(0^{\circ} \mathrm{C}\right.$ até $\left.120^{\circ} \mathrm{C}\right)$ corresponde à perda das moléculas de água livre. Entre $\left(400^{\circ} \mathrm{C}\right.$ até $\left.500^{\circ} \mathrm{C}\right)$ constata-se a transformação da caulinita em metacaulinita. Os resultados comprovam que a temperatura de $700^{\circ} \mathrm{C}$ é suficiente para a transformação da caulinita em metacaulinita dado que as curvas de TGA/DSC mostram que a desidroxilação tem inicio a partir de $480{ }^{\circ} \mathrm{C}$ 


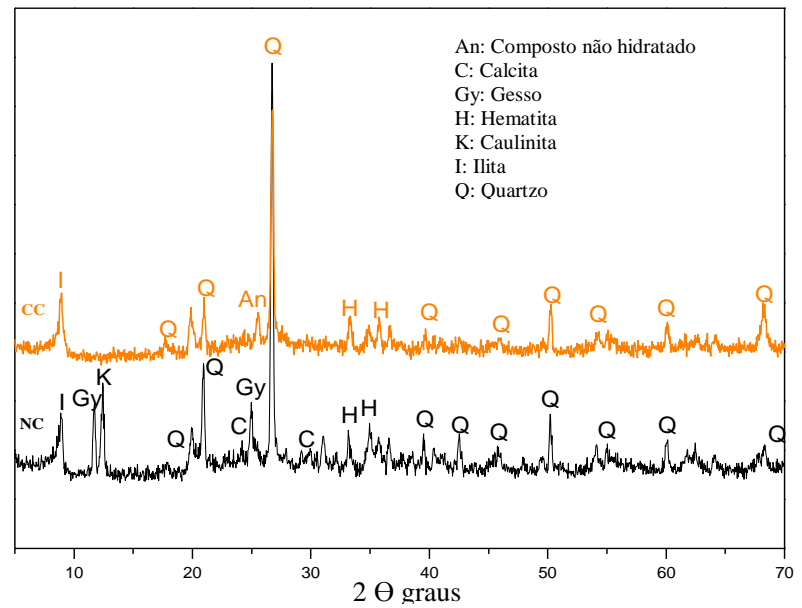

Figura 1: Espectros de difracção de raios-X: Embaixo argila (NC) e acima argila calcinada (CC).

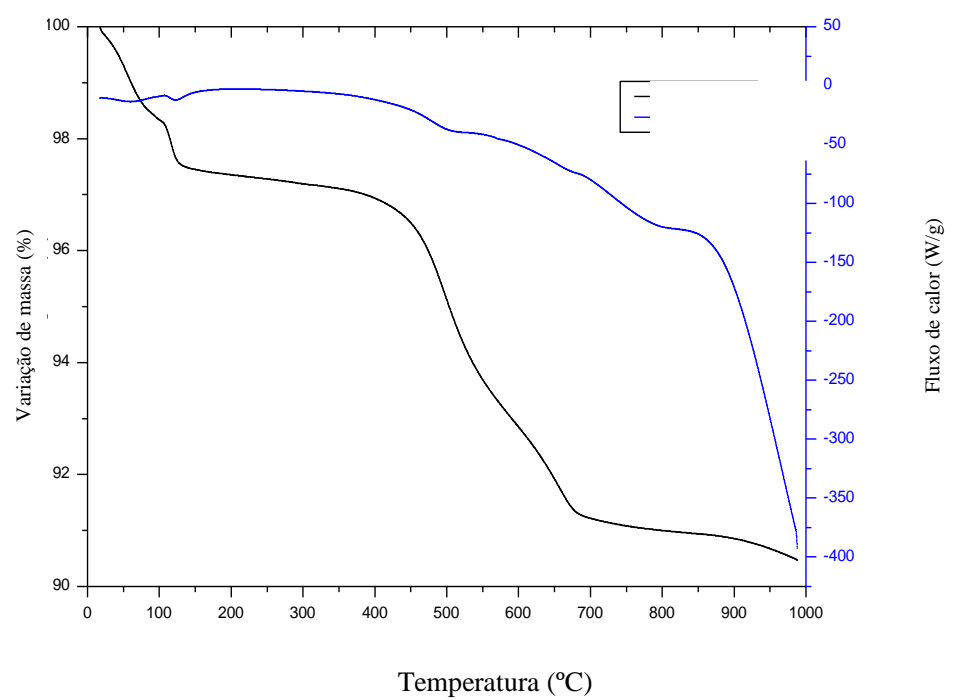

Figura 2: Curvas ATD/TG da argila

A Figura 3 apresenta imagens da microestrutura da argila onde é possível constatar algum grau de aglomeração após a calcinação. A distribuição cumulativa das dimensões das partículas de argila foi obtida por difração de raios laser utilizando um equipamento Analysette 22 Microtec da Fritsch. Uma melhor caracterização dessa aglomeração (aumento do diâmetro médio) é visivel na Figura 4 e principalmente na Tabela 2. A mesma pode ficar a dever-se a eventual fusão do feldspatos de potássio que ocorre por volta dos $350{ }^{\circ} \mathrm{C}$.
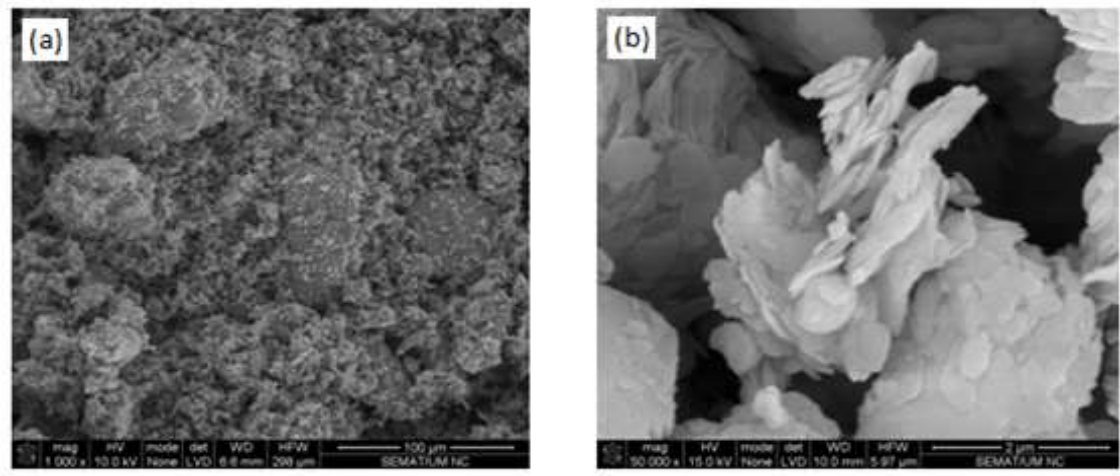

Figura 3: Microestrutura da argila: antes e depois da calcinação 
TAHRI, S.; SAMET, B; PACHECO-TORGAL, F.; AGUIAR, J.; BAKLOUTI, S. Matéria, v. 21, n. 1, pp. 213 - $226,2016$.
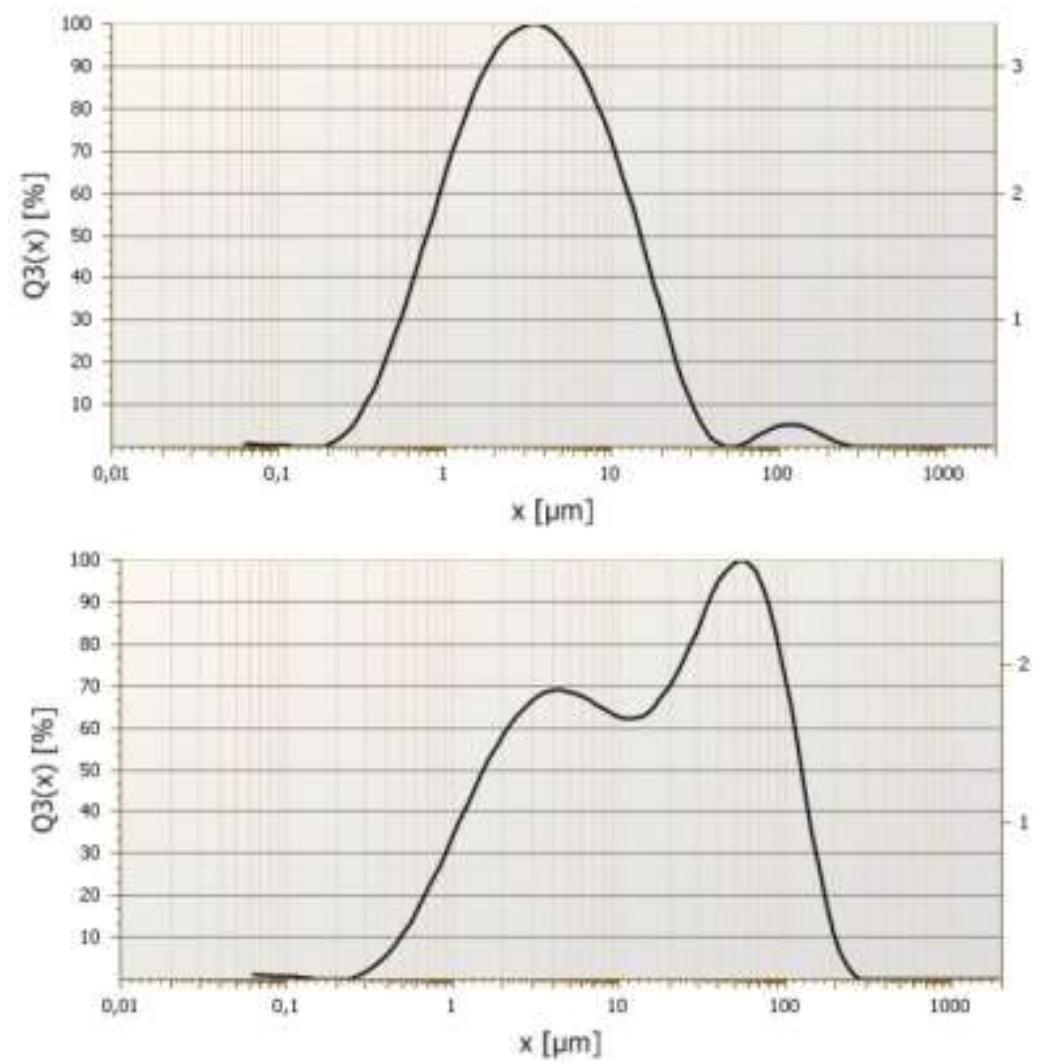

Figura 4: Distribuição da dimensão das partículas de argila: Em cima argila e em baixo argila calcinada.

Tabela 2: Valores do diâmetro médio (D50, D90) das partículas de argila

\begin{tabular}{|l|c|c|}
\hline Argila & $\mathbf{D 5 0} /(\boldsymbol{\mu m})$ & $\mathbf{D 9 0} /(\boldsymbol{\mu m})$ \\
\hline Antes da calcinação & 3,4 & 14,2 \\
\hline Argila calcinada & 15,9 & 89,4 \\
\hline
\end{tabular}

A Figura 5 apresenta os espectros de espectroscopia de infravermelhos. Nestes é possível constatar a presença de picos de caulinita $\left(3693-3619 \mathrm{~cm}^{-1}\right)$ [17] o que mostra que a temperatura utilizada não foi suficiente para fazer a transformação de toda a fase de caulinita em metacaulinita. 


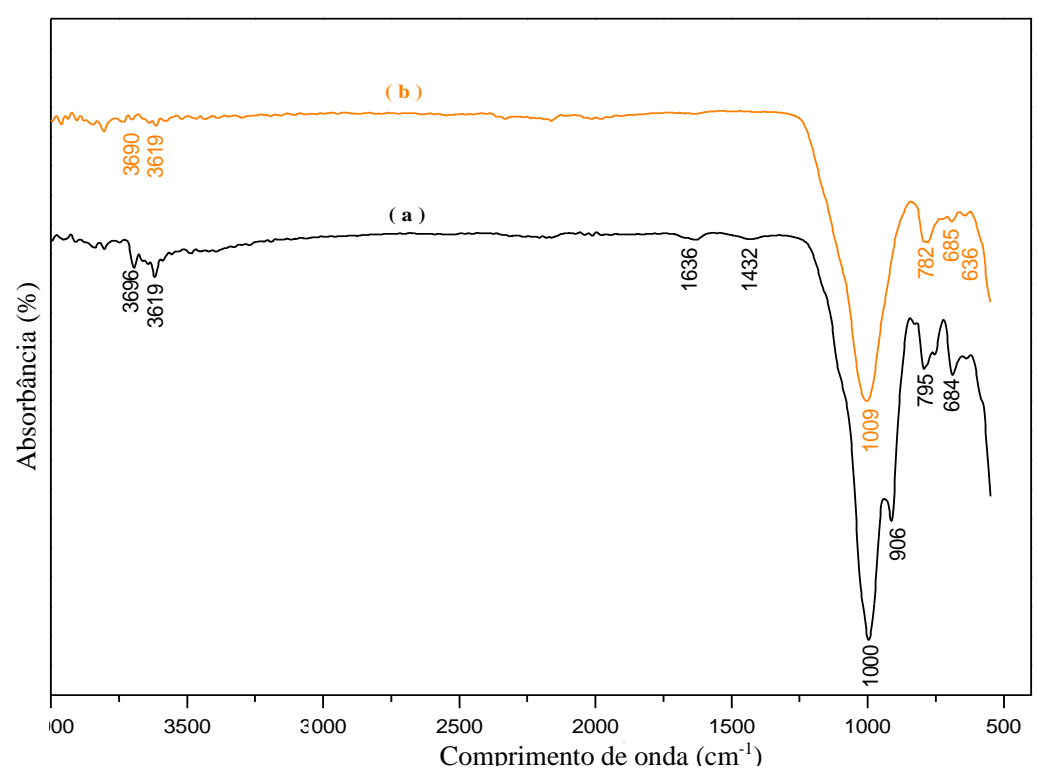

Figura 5: Espectros de infravermelhos: Embaixo argila e acima argila calcinada.

\subsection{Composição, preparação das argamassas e ensaios}

As argamassas geopoliméricas utilizadas na presente investigação são constituídas por argila da Tunísia calcinada, cal apagada, areia e um ativador à base de silicato de sódio e hidróxido de sódio (Tabela 3). A Figura 6 apresenta uma imagem das argamassas geopoliméricas. Na tabela 4 apresenta-se um segundo conjunto de composições elaboradas a partir da composição G1 R3 e nas quais houve lugar à redução de $20 \%$ do ativador alcalino e à substituição parcial de argilas por cinzas volantes e por metacaulim. Esta nova fase pretendeu optimizar em termos de desempenho mecânico as misturas analisadas na fase 1. Na preparação das argamassas geopoliméricas foi utilizada uma solução de hidróxido sódio com uma concentração de 12M. A mesma foi obtida a partir da dissolução de hidróxido de sódio em palhetas com um grau de pureza de $99 \%$. Utilizou-se também silicato de sódio com uma densidade de $1350 \mathrm{~kg} / \mathrm{m}^{3}$. A razão mássica silicato de sódio e hidróxido de sódio foi de $2,5\left(\mathrm{Na}_{2} \mathrm{SiO}_{3} / \mathrm{NaOH}=2,5\right)$. As materiais foram misturados com uma misturadora Hobart durante 3 minutos.

Tabela 3: Composição das argamassas - Fase 1

\begin{tabular}{|c|c|c|c|c|c|c|}
\hline \multirow{2}{*}{ Misturas } & \multirow{2}{*}{$\begin{array}{l}\text { Argila } \\
\text { calcinada } \\
\text { (g) }\end{array}$} & \multirow{2}{*}{$\begin{array}{l}\text { Cal } \\
(\mathrm{g})\end{array}$} & \multirow{2}{*}{$\begin{array}{l}\text { Areia } \\
(\mathrm{g})\end{array}$} & \multicolumn{2}{|c|}{ Activador (g) } & \multirow{2}{*}{$\begin{array}{l}\text { (Cal+Argila calcina- } \\
\text { da)/areia }\end{array}$} \\
\hline & & & & $\mathrm{Na}_{2} \mathrm{SiO}_{3}$ & $\mathrm{NaOH}$ & \\
\hline G1R2 & 674 & 75 & 1496 & 535 & 213 & $1: 2$ \\
\hline G1R3 & 674 & 75 & 2250 & 535 & 213 & $1: 3$ \\
\hline G1R4 & 674 & 75 & 2992 & 535 & 213 & $1: 4$ \\
\hline
\end{tabular}
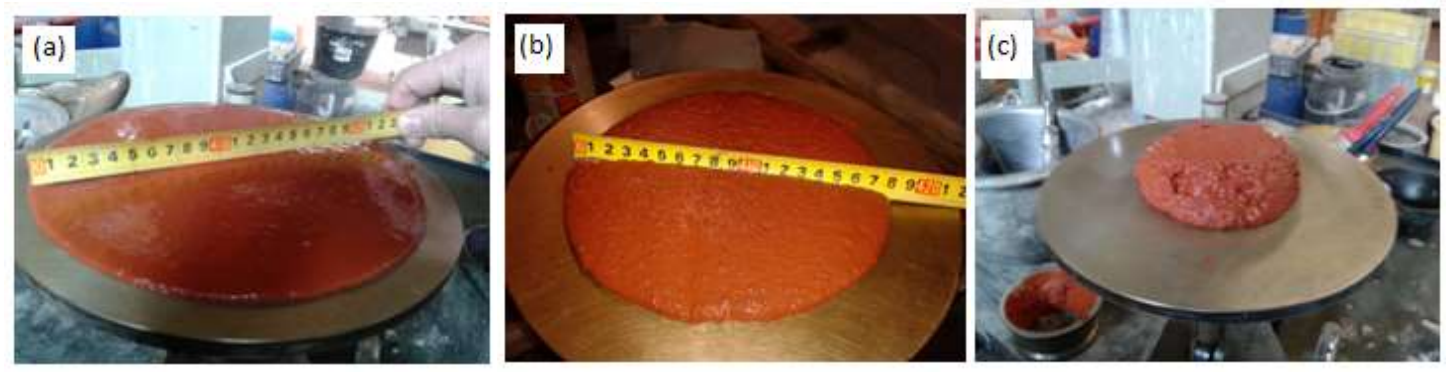

Figura 6: Imagem das argamassas geopoliméricas: (a) G1R1, (b) G1R3, (c) G1R4 
Tabela 4: Composição das argamassas - Fase 2

\begin{tabular}{|c|c|c|c|c|c|c|c|c|}
\hline Misturas & $\begin{array}{l}\text { Argila calcinada } \\
\text { (g) }\end{array}$ & $\begin{array}{l}\text { Cal } \\
\text { (g) }\end{array}$ & $\begin{array}{l}\text { Areia } \\
\text { (g) }\end{array}$ & $\begin{array}{l}\text { Activa } \\
\mathrm{Na}_{2} \mathrm{Si}\end{array}$ & $\begin{array}{l}\text { dor }(\mathbf{g}) \\
{ }_{3} \mathrm{NaOH}\end{array}$ & $\begin{array}{l}\text { Cinzas } \\
\text { V.(g) }\end{array}$ & $\begin{array}{l}\text { Mk } \\
(\mathrm{g})\end{array}$ & $\begin{array}{l}(\mathrm{Cal}+\mathrm{Argila} \\
\text { calcinada)/areia }\end{array}$ \\
\hline G1R_3_80\%_REF & 1265 & 141 & 4216 & 802 & 322 & 0 & 0 & \multirow{6}{*}{$1: 3$} \\
\hline G1R3_80\%_10\%FA & 1138 & 141 & 4216 & 802 & 322 & 126 & 0 & \\
\hline G1R3_80\%_15\%FA & 1075 & 141 & 4216 & 802 & 322 & 189 & 0 & \\
\hline G1R3_80\%_10\%Mk & 1138 & 141 & 4216 & 802 & 322 & 0 & 127 & \\
\hline G1R3_80\%_15\%Mk & 1075 & 141 & 4216 & 802 & 322 & 0 & 190 & \\
\hline G1R3_80\%_30\%Mk & 885 & 141 & 4216 & 802 & 322 & 0 & 379 & \\
\hline
\end{tabular}

As análises de microscopia electrônica de varrimento foram efectuadas usando um microscópio electrônico Phillip 30.

A espectroscopia de infravermelhos foi realizada com um espectrómetro Perkin Elmer FTIR Spectrum BX utilizando pastilhas de brometo de potássio (KBr) seguinda a técnica descrita por Zhang et al. [18] para a análise de espectros de infravermelhos na região espectral $550-4000 \mathrm{~cm}^{-1}$, em virtude do brometo de potássio não apresentar qualquer pico quando sujeito à radiação de infravermelhos. As pastilhas são compostas por $1 \mathrm{mg}$ de pó do material a ensaiar misturada com $100 \mathrm{mg}$ de brometo de potássio.

O espectro de infra-vermelhos é gerado como consequência da absorção da radiação electromagnética em frequências que se correlacionam com modos vibratórios específicos de cada molécula, sendo que em cada momento a sua energia é dada pela soma, das suas componentes eléctrica, rotacional, de translação e vibracional, que é a componente de maior energia e que corresponde à energia das moléculas quando os seus átomos vibram a partir do centro da sua ligação química [19]. O espectro vibratório de cada molécula é uma propriedade física única e característica de cada molécula, desta forma o espectro de infravermelhos pode ser usado para caracterizar um determinado composto molecular por comparação com espectros previamente guardados numa base de dados [20].

\section{RESULTADOS E DISCUSSÃO}

A Figura 7a apresenta curvas da análise térmica diferencial de argamassas geopoliméricas onde se constata a perda de água no intervalo $\left(0^{\circ} \mathrm{C}-120^{\circ} \mathrm{C}\right)$ a qual é similar nas diferentes argamassas. Informação idêntica pode retirar-se das curvas de termogravimetria onde são visíveis picos endotérmicos relativos à libertação de H-O$\mathrm{H}$.

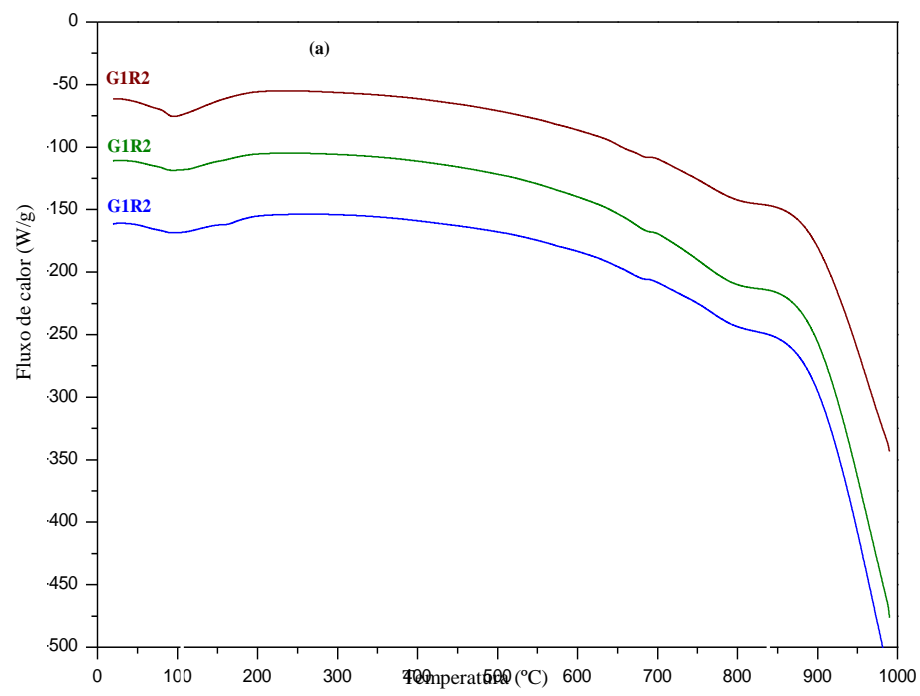




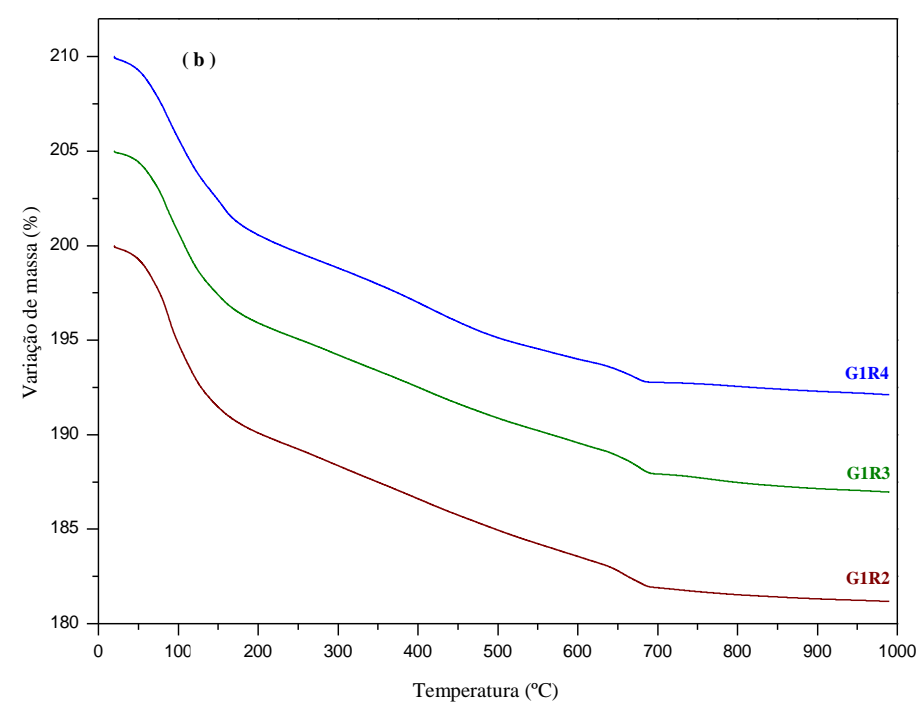

Figura 7: ATD (a); TG (b) das argamassas geopolíméricas.

A Figura 8 apresenta os espectros de difracção e de raios-X de argamassas geopoliméricas. A presença de metacaulinita é confirmada por um pico $\left(2 \theta=12^{\circ}\right)$. Constatam-se ainda a presença de picos de quartzo $\left(21.3^{\circ}, 26,9^{\circ}, 40^{\circ}, 50^{\circ}, 60^{\circ}, 62^{\circ}, 64^{\circ}\right.$ and $\left.67^{\circ}\right)$ e de calcita o que mostra que estes minerais não são dissolvidos durante a geopolimerização. A presença de um zeólito é visível nos espetros das três argamassas, o qual ocorre para o mesmo valor de $2 \Theta\left(31^{\circ}\right)$ embora com diferentes intensidades. Estes costumam ser visíveis em geopolímeros com um elevado teor de água [21].

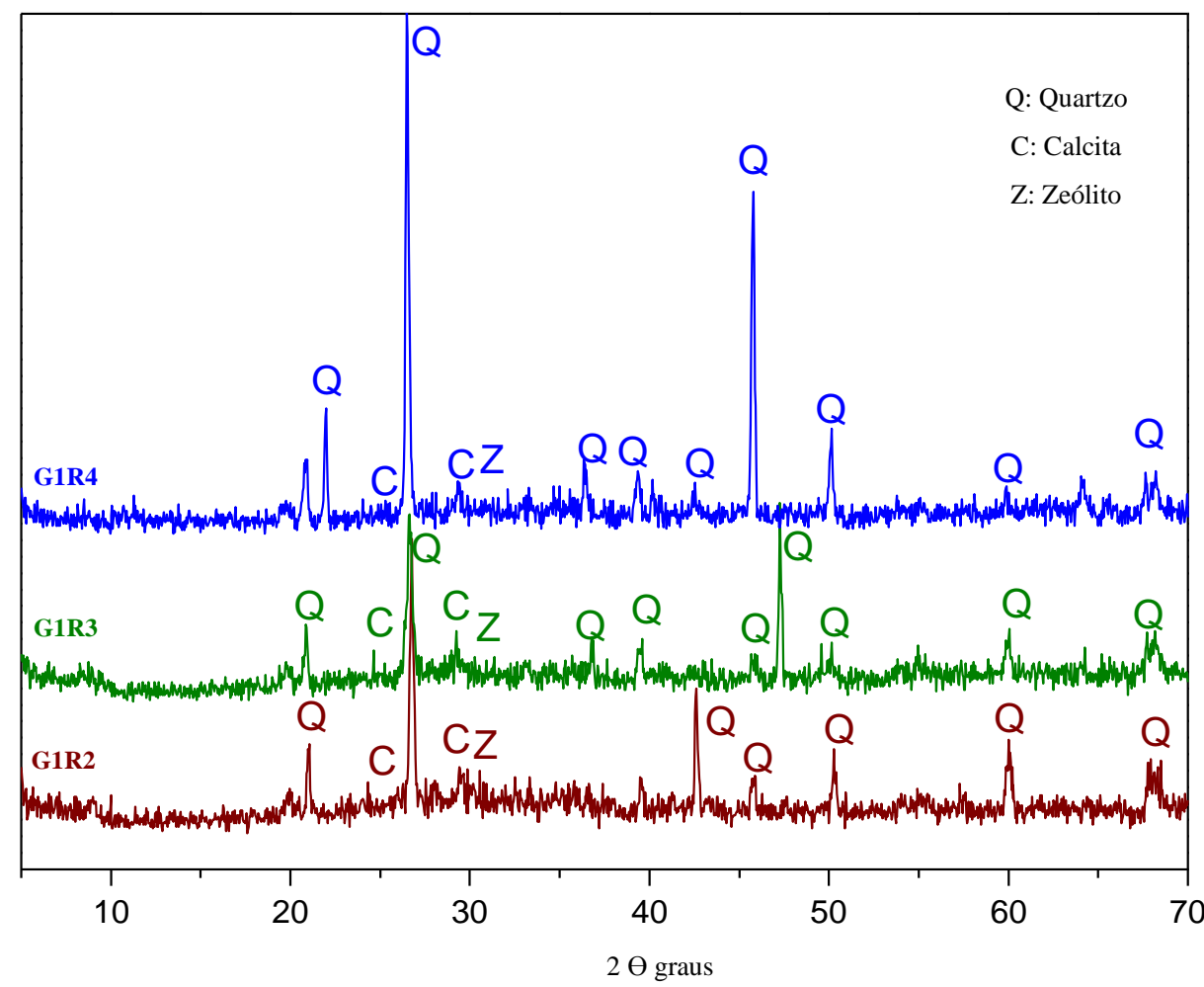

Figura 8: Espectros de difração de raios-X das argamassas geopoliméricas 
A Figura 9 apresenta espectros de difração de raios-X de argamassas geopoliméricas elaboradas a partir da composição G1 R3 quer com substituição de argila da Tunisia por metacaulim quer também com substituição da mesma argila por cinzas volantes.

As curvas da espectroscopia de infravermelhos de argamassas geopoliméricas são apresentadas na Figura 10. Nela são visíveis vibrações características de aluminosilicatos. Nota-se uma mudança de $975 \mathrm{~cm}^{-1}$ para valores inferiores que corresponde à vibração das bandas de $\mathrm{Si}-\mathrm{O}-\mathrm{Al}$ e $\mathrm{Si}-\mathrm{O}-\mathrm{Si}$ associadas à reação de geopolimerização. $\mathrm{O}$ valor de $870 \mathrm{~cm}^{-1}$ corresponde à vibração do $\mathrm{Si}-\mathrm{OH}$. As vibrações do $\mathrm{Al}-\mathrm{O}-\mathrm{Si}$ estão associadas às bandas entre $600-800 \mathrm{~cm}^{-1}$. A absorção de $782 \mathrm{~cm}^{-1}$ corresponde à presença de quartzo [22]. A

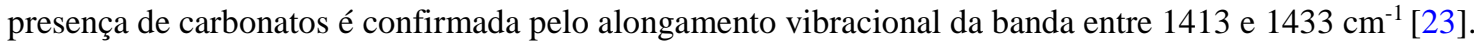

O dióxido de carbono atmosférico reage com partículas de sódio livre gerando carbonato de sódio. A presença de água está associada ao valor da banda em $1645 \mathrm{~cm}^{-1}$. À medida que se processa a cura das argamassas geopoliméricas estas bandas apresentam uma redução da sua intensidade. Esta redução também pode ficar a dever-se à presença de estruturas zeolíticas (fases cristalinas) que necessitam de mais moléculas de água do que a fase geopolímérica (amorfa).

A Figura 11 apresenta as curvas da espectroscopia de infravermelhos de argamassas geopoliméricas elaboradas a partir da composição G1 R3 quer com substituição de argila da Tunisia por metacaulim quer também com substituição da referida argila por cinzas volantes. As bandas na região 1000 e $1004 \mathrm{~cm}^{-1}$ correspondem à ligação Si-O-Si [24-26]. As bandas em $776 \mathrm{~cm}^{-1}$ e $692 \mathrm{~cm}^{-1}$ confirmam a presença de quartzo [27]. Já as pequenas bandas $\left(1420,1422 \mathrm{~cm}^{-1} \mathrm{e} 1489 \mathrm{~cm}^{-1}\right)$ estão associadas ao alongamento assimétrico das ligações $\mathrm{O}-\mathrm{C}-\mathrm{O}$ do $\mathrm{CO}_{3}{ }^{2-}$ comprovativas da carbonatação atmosférica das diferentes argamassas geopoliméricas.

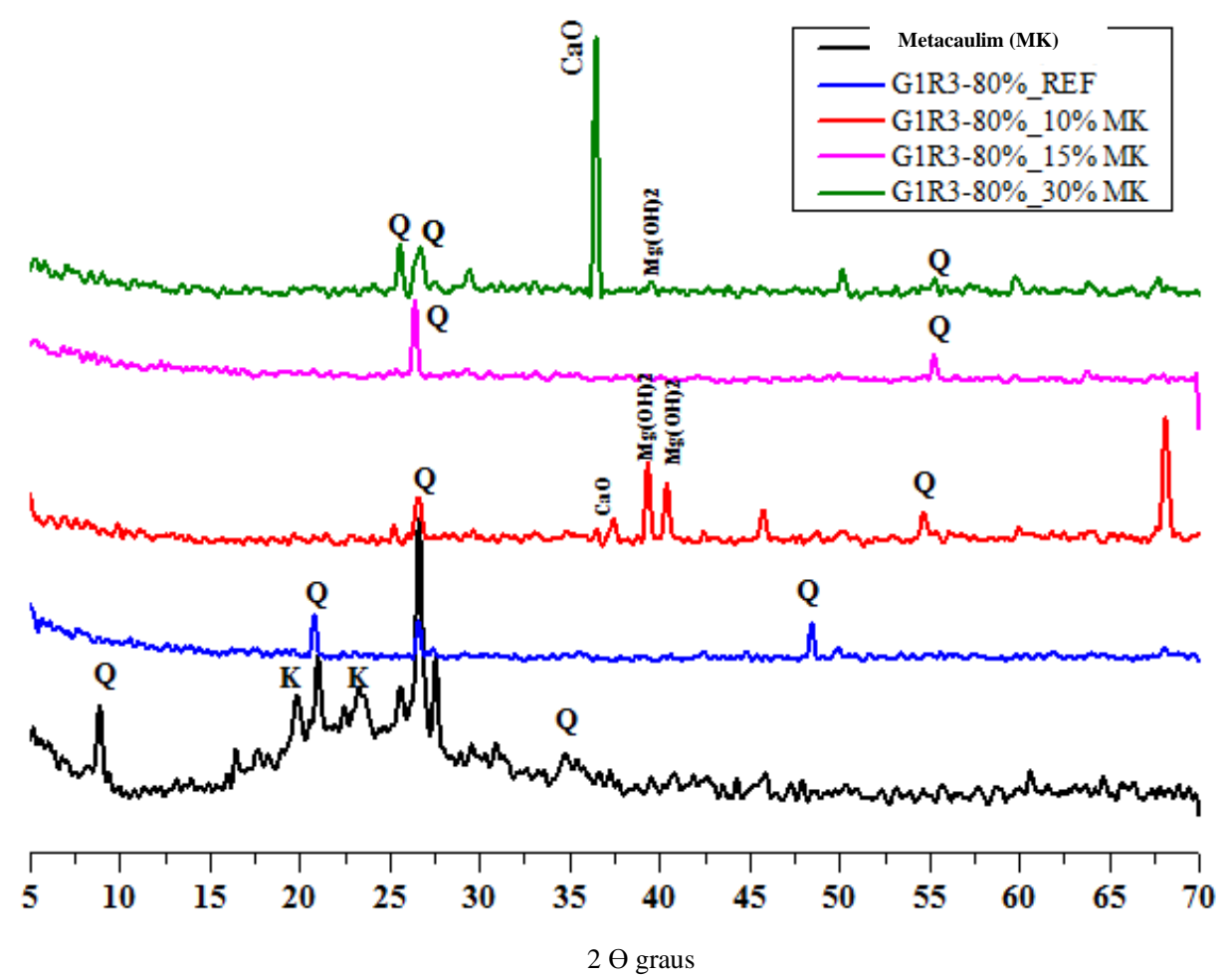




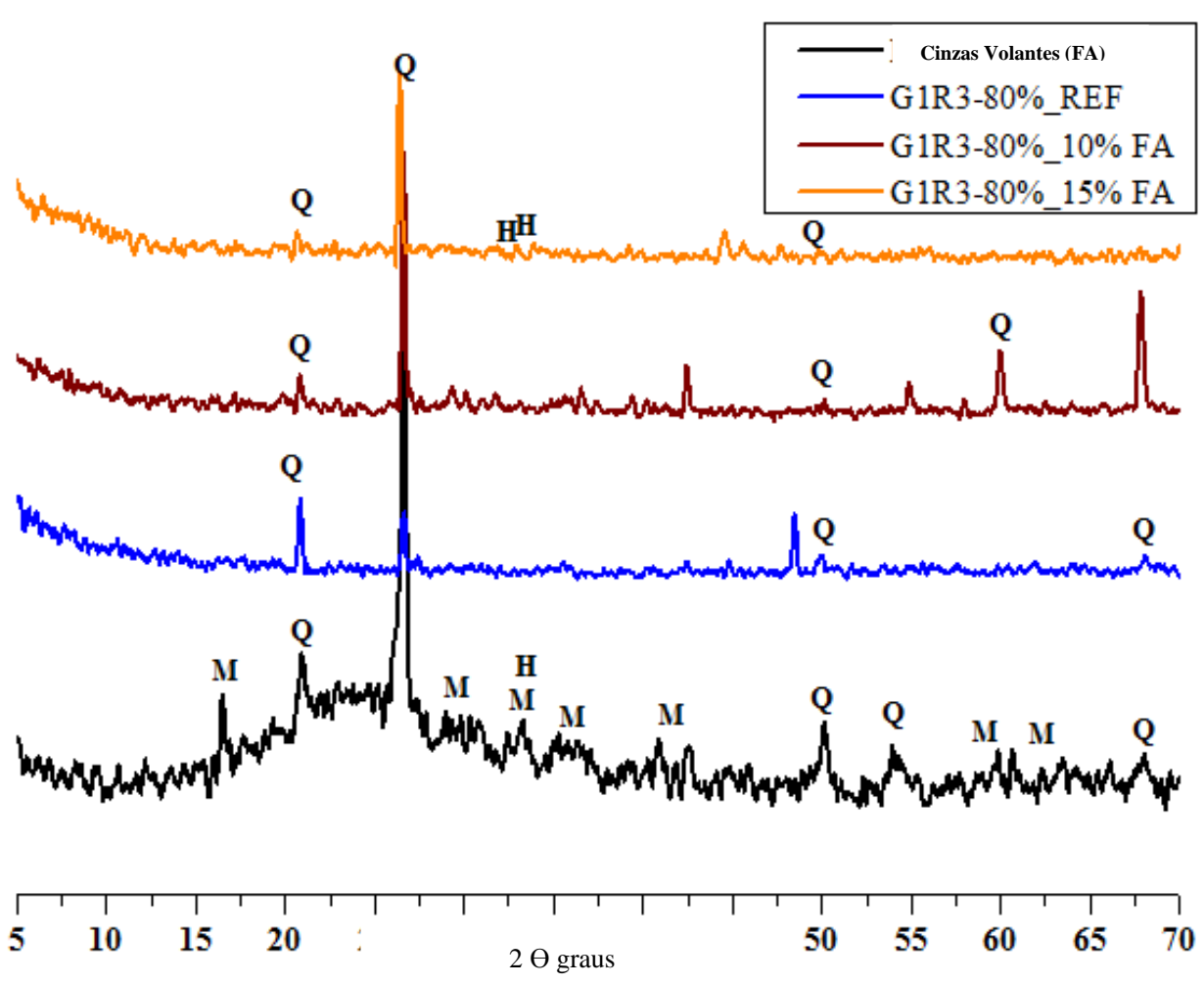

Figura 9: Espectros de difração de raios- $X$ de argamassas geopoliméricas elaboradas

a partir da composição G1 R3: a) com substituição de argila por metacaulim;

b) com substituição de argila por cinzas volantes

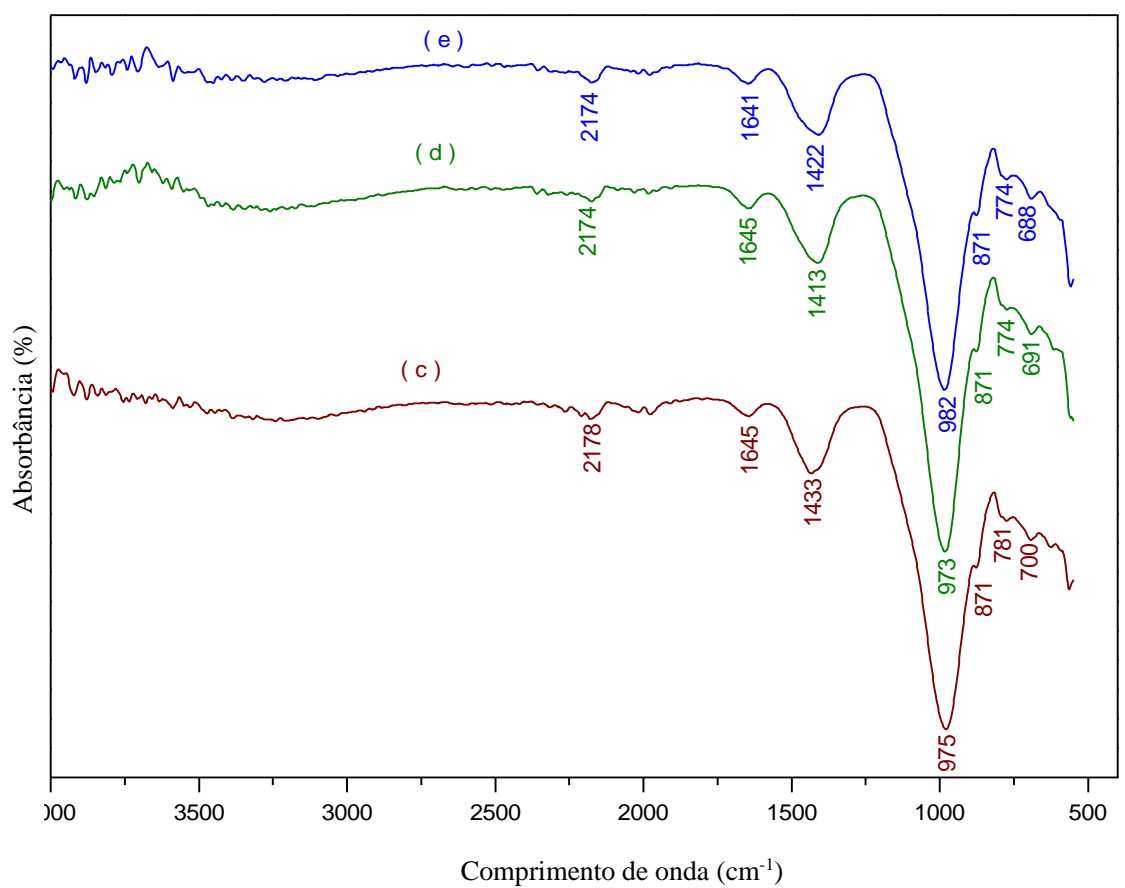

Figura 10: Espectros de espectroscopia de infravermelhos de argamassas geopoliméricas 
a)

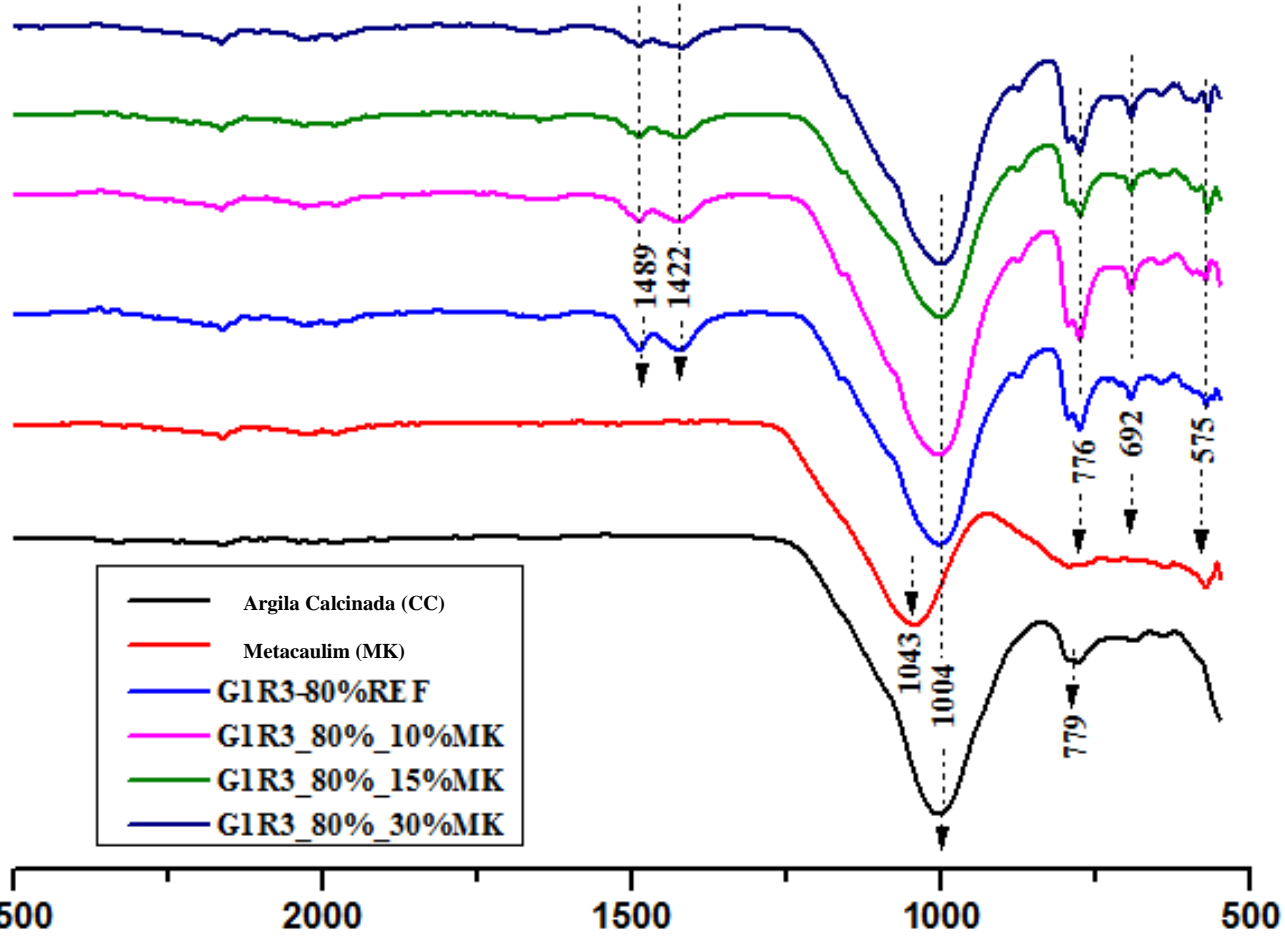

b)

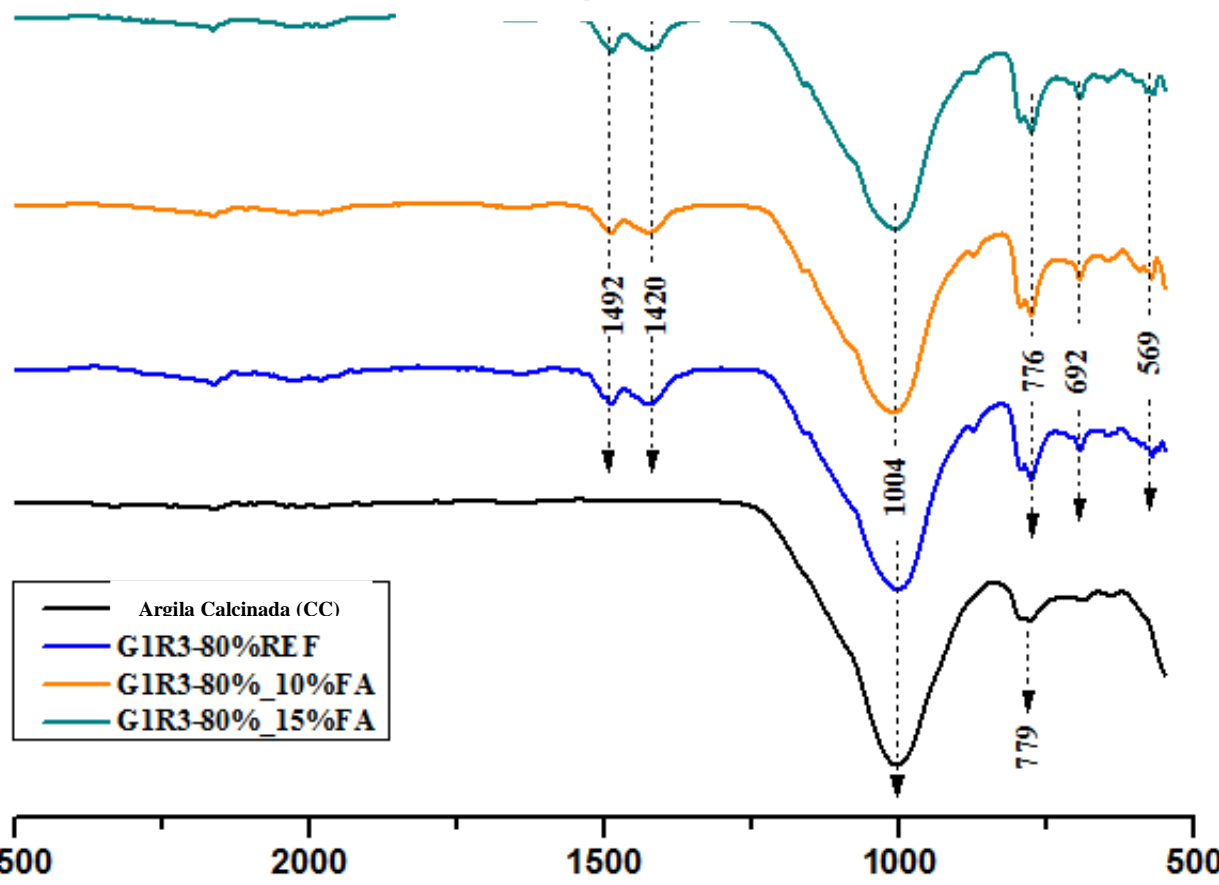

Comprimento de onda $\left(\mathrm{cm}^{-1}\right)$

Figura 11: Espectros de espectroscopia de infravermelhos de argamassas geopoliméricas elaboradas

a partir da composição G1 R3: a) com substituição de argila por metacaulim; b) com substituição de argila por cinzas volantes

A Figura 12 apresenta imagens da microestrutura das argamassas geopoliméricas estudadas na fase 1. Comprova-se a existência de uma microestrutura homogenea nas diferentes argamassas a par de alguma microfissuração provocada pela elevada de retração daquelas [28]. 
A Figura 13 apresenta imagens da microestrutura das argamassas geopoliméricas elaboradas a partir da composição G1 R3 quer com substituição de argila da Tunisia por metacaulim quer também com substituição de argila por cinzas volantes. As mesmas confirmam que a argamassa com $30 \%$ (f) de metacaulim não apresenta microfissuração o que está de acordo com o facto desta argamassa ter apresentado o menor valor de retracção.

As imagens mostram também a presença de partículas que não reagiram durante a fase de geopolimerização e também a presença de alguma macro e micro porosidade (b).
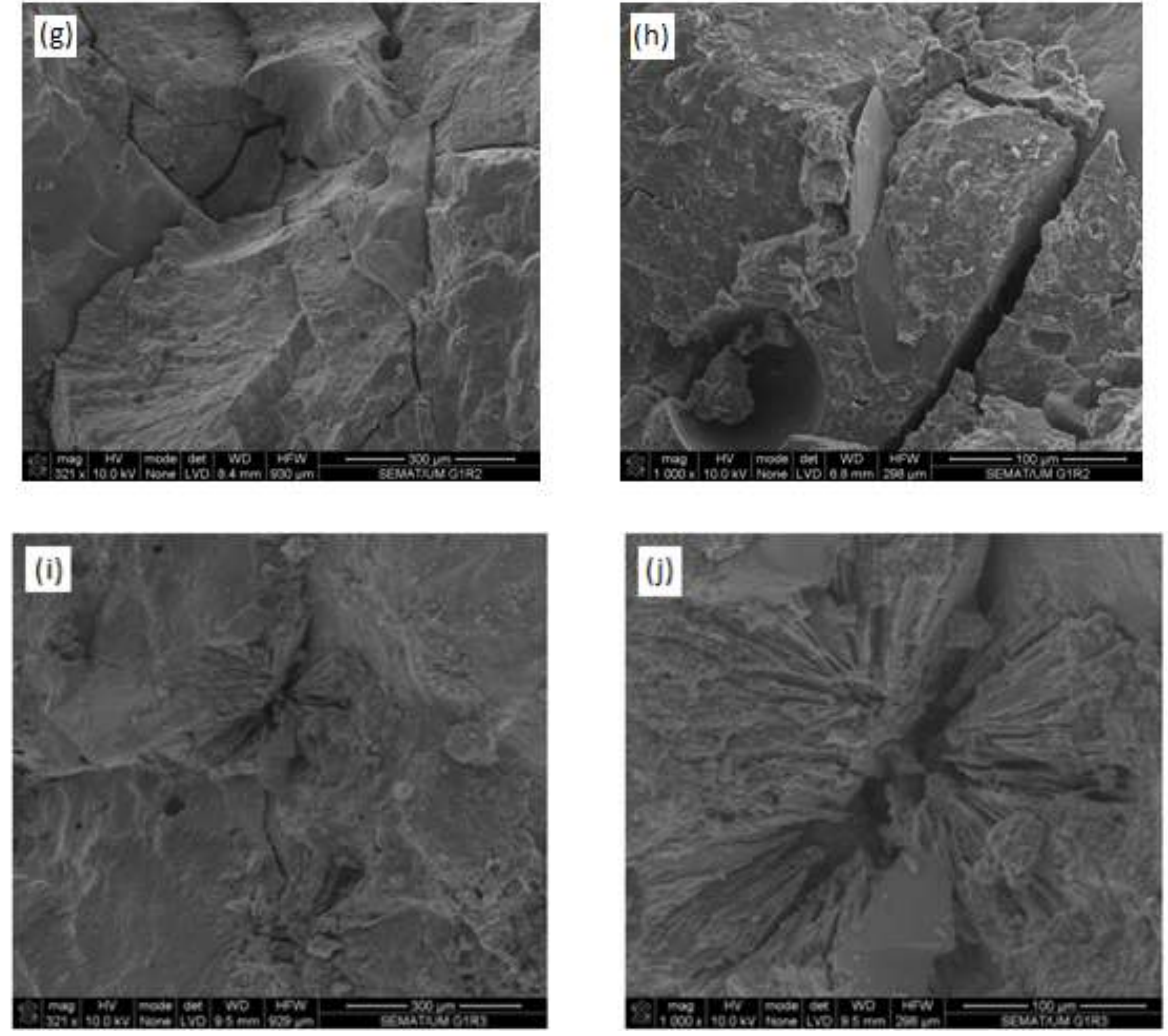

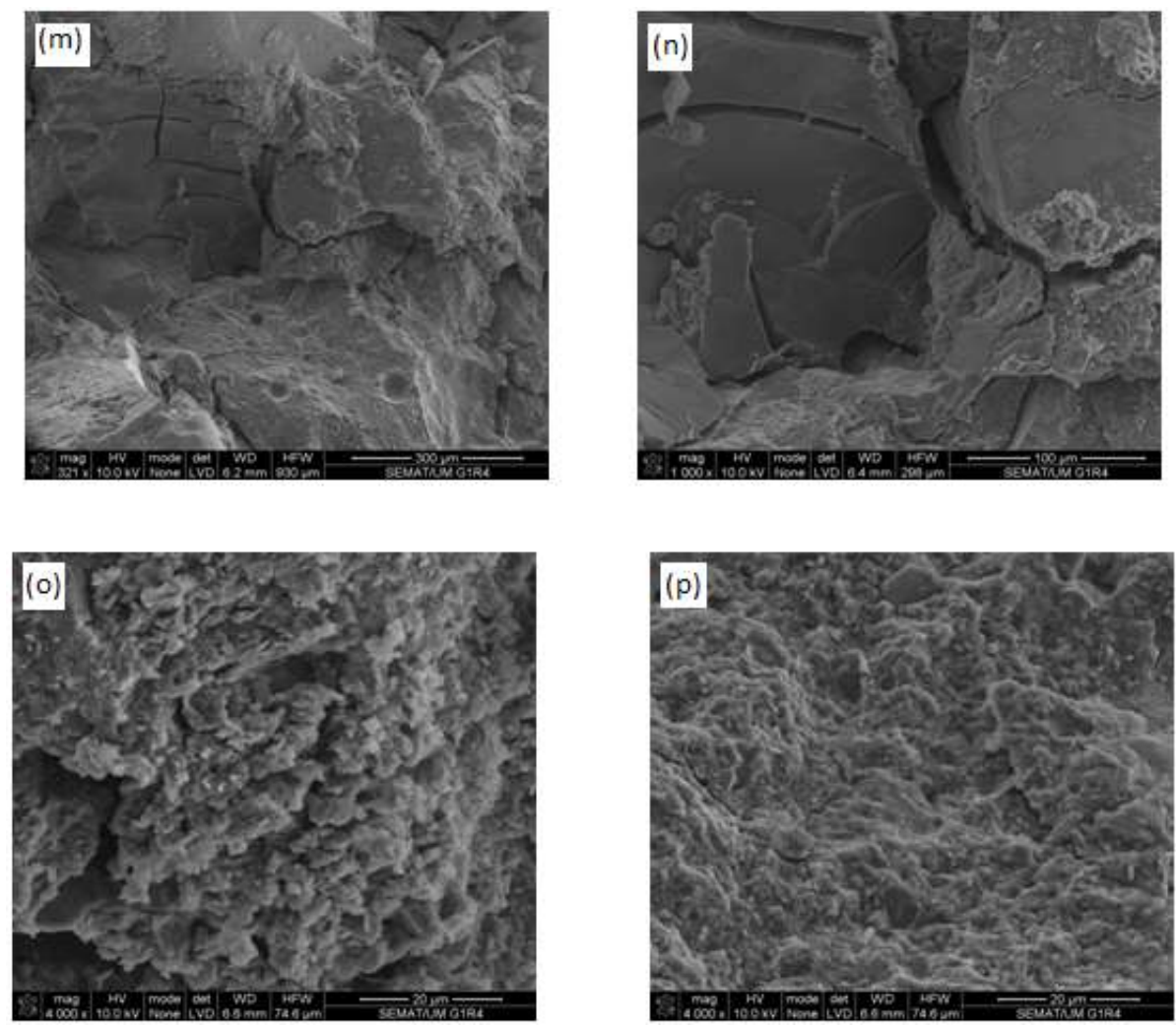

Figura 12: Microstrutura de argamassas geopoliméricas: G1R2 (g),(h);

G1R3 (i),(j); G1R4 (m),(n),(o),(p)
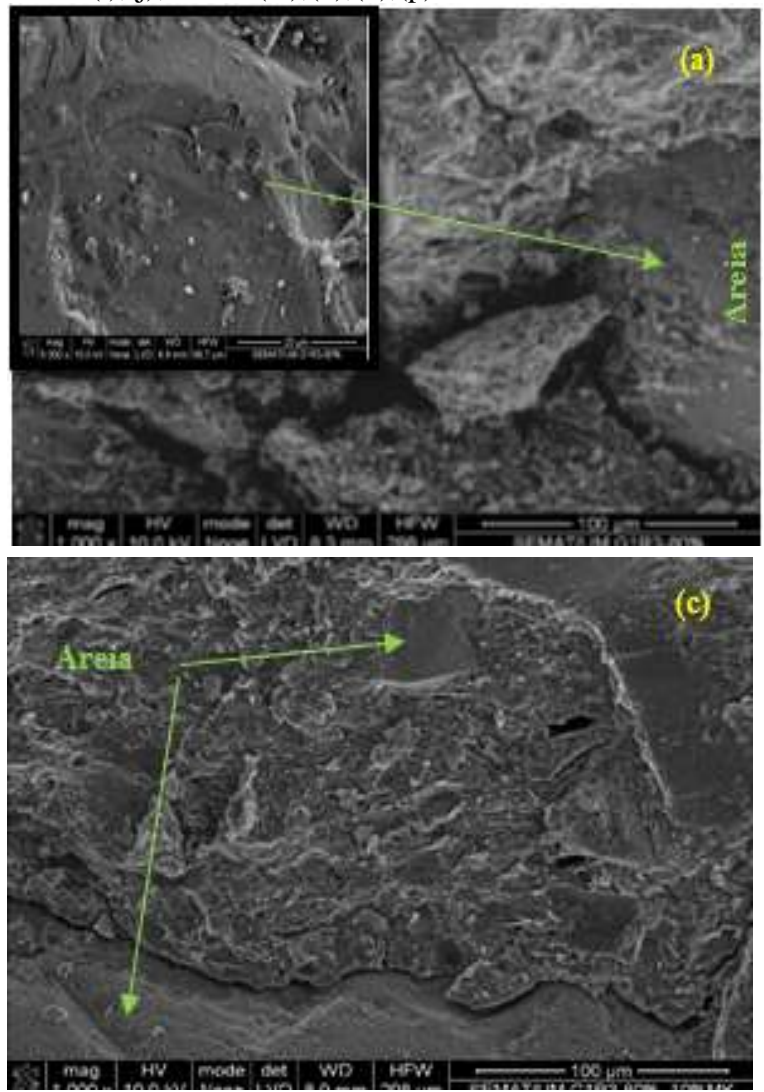
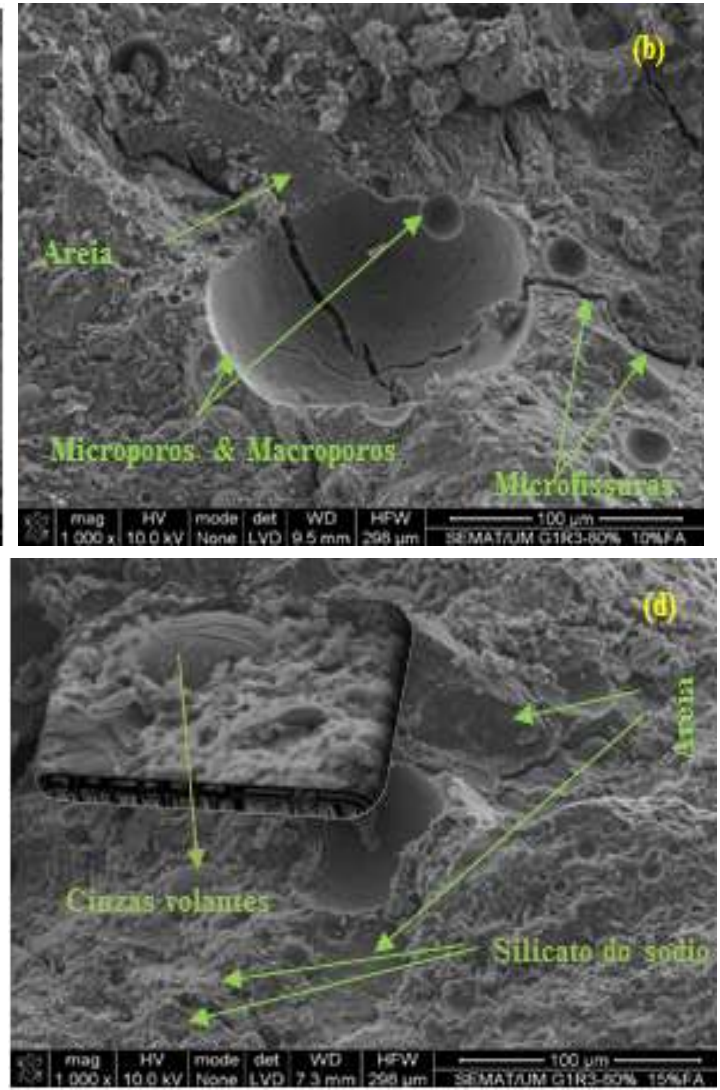

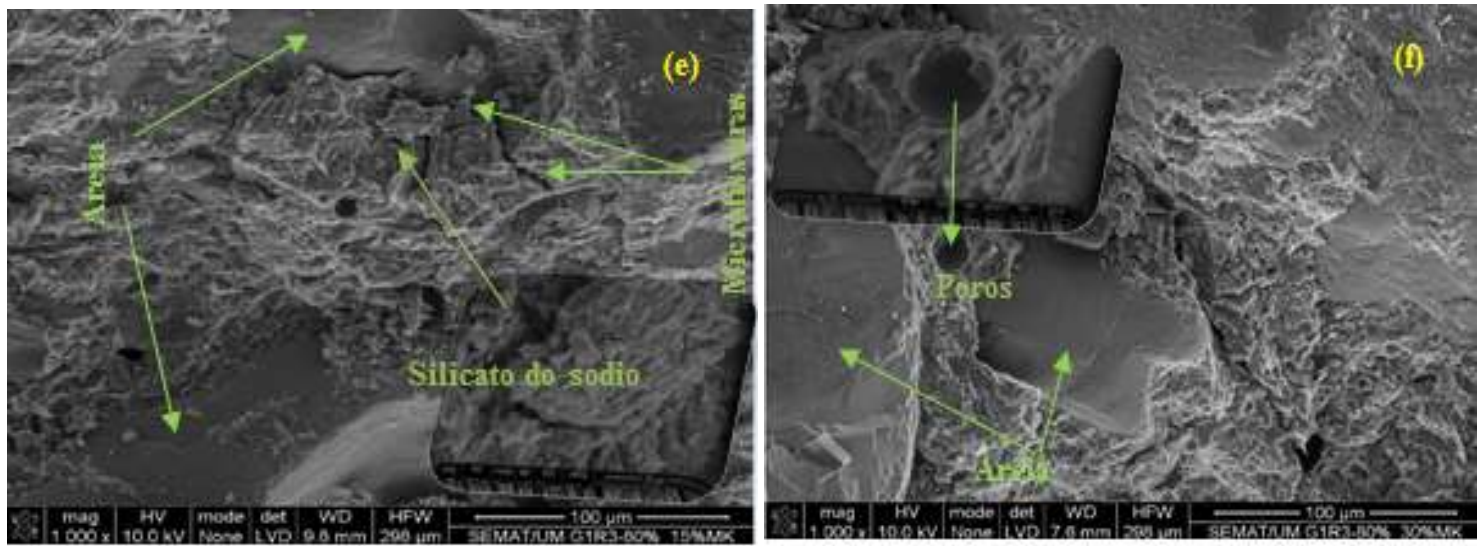

Figura 13: Microstrutura de argamassas geopoliméricas elaboradas a partir da composição G1 R3:

a) (G1R3-80\%_REF); b) G1R3-80\%-10\%FA; c) G1R3-80\%-10\%MK; d) G1R3-80\%-15\%FA;

e) G1R3-80\%-15\%MK; f) G1R3-80\%-30\%MK

\section{CONCLUSÕES}

Os custos associados à reabilitação de estruturas de concreto apresentam valores astronómicos rondando vários triliões de dólares. As investigações sobre argamassas de reabilitação assumem nesse contexto uma particular importância. O presente artigo analisou argamassas geopoliméricas à base de argilas da Tunisia calcinadas. Foi feita uma caracterização das propriedades da argila utilizada com recurso a análise térmica doferencial e termogravimétrica, difração de raios-X, espectroscopia de infravermelhos e microestrutura. Foi também feita uma análise dos produtos de hidratação das argamassas que comprovou a existência de fases geopoliméricas.

\section{BIBLIOGRAFIA}

[1] DAVALOS, J.F. Advanced materials for civil infrastructure rehabilitation and protection, Seminar at The Citty College of New York, New York, 2012.

[2] HOLLAWAY, LC., "Key issues in the use of fibre reinforced polymer (FRP) composites in the rehabilitation and retrofitting of concrete structure", In: Karbhari, V.M., Lee, L.S. (Eds.), Service life estimation and extension of civil engineering structures, Woodhead Publishing Limited Abington Hall, Cambridge, 2011.

[3] EMMONS, P., VAYSBURD, A. "Factors affecting the durability of concrete repair: the contractor's viewpoint", Construction and Building Materials, v.8, pp.5-16, 1994.

[4] EMMONS, P., VAYSBURD, A. "Total system concept - necessary for improving the performance of repaired structures", Construction and Building Materials, v.10, pp.69-75, 1996.

[5] PACHECO-TORGAL, F., FUCIC, A., JALALI, S. Toxicity of Building Materials, Woodhead Publishing Limited Abington Hall, Cambridge, UK, 2012.

[6] PACHECO-TORGAL, F., LABRINCHA, J.A., JALALI, S., et al., Eco-efficient concrete, Woodhead Publishing Limited Abington Hall, Cambridge, UK, 2013.

[7] VAN DEVENTER, J., PROVIS, J., DUXSON, P., "Technical and commercial progress in the adoption of geopolymer cement", Minerals Engineering, v. 29, pp.89-104, 2012.

[8] PACHECO-TORGAL, F., CASTRO-GOMES, J., JALALI, S. “Alkali - activated binders: a review Part 1 Historical background, terminology, reaction mechanisms and hydration products", Construction and Building Materials, v.22, pp.1305-1314, 2008.

[9] PACHECO-TORGAL, F., CASTRO-GOMES, J., JALALI, S. “Alkali - activated binders: a review Part 2 About materials and binders manufacture", Construction and Building Materials, v.22, pp.1315-1322, 2008.

[10] LI, C., SUN, H., LI, L. “A review: The comparison between alkali-activated slag (Si+Ca) and metakaolin (Si+Al) cements”, Cement and Concrete Research, v.40, pp.1341-1349, 2010.

[11] PROVIS, J.L. "Geopolymers and other alkali activated materials: why, how, and what?", Materials and Structures, v.47, pp.11-25, 2014.

[12] PACHECO-TORGAL, F., ABDOLLAHNEJAD, Z., MiRALDO, S., et al., "An overview on the poten- 
tial of geopolymers for concrete infrastructure rehabilitation", Construction and Building Materials, v.36, pp.1053-1058, 2012.

[13] PACHECO-TORGAL, F., CASTRO-GOMES, J., JALALI, S. "Adhesion characterization of tungsten mine waste geopolymeric binder. Influence of OPC concrete substrate surface treatment. Construction and Building Materials, v.22, pp.154-61, 2008.

[14] KHAN, M.I., ALMUSALLAM, T.H., ALSAYED, S.H., et al., Bond characteristics of substrate concrete and repair materials, Concrete Repair, Rehabilitation and Retrofitting III - Proceedings of the 3rd International Conference on Concrete Repair, Rehabilitation and Retrofitting, ICCRRR 2012, pp. 1041-1045, 2012.

[15] MACKENZIE, RC. The differential thermal investigation of clays, London, Mineralogical Society, 1957.

[16] BOUAZIZ, R., ROLLET, AP. L'analyse thermique, L'examen des processus chimiques, Tome 2, Paris, Gautier-Villars; 1972.

[17] KAKALI, G., PERRAKI, T., TSIVILIS, S. et al., "Thermal treatment of kaolin: the effect of mineralogy on the pozzolanic activity", Applied Clay Science, v.20, pp.73-80, 2001.

[18] ZHANG, M., WRUCK, B., GRAEME - BARBER, A., et al., "Phonon-spectroscopy on alkali-feldspar: phase transitions and solid solutions", American Mineralogist, v. 81, 92-104, 1996.

[19] COATES, J. Interpretation of infrared spectra, a pratical approach, In Encyclopedia of Analytical Chemistry. John Wiley \& Sons Ltd, Chichester, 2000

[20] HOLLAS, J.M., Modern spectroscopy. $3^{\text {rd }}$ edition, John Wiley \& Sons Ltd New York, 1996

[21] WANG, H., LI, H., YAN, F. "Synthesis and mechanical properties of metakaolin-based geopolymer", Colloids Surfaces A: Physicochemical and Engineering Aspects, v.268, pp.1-6, 2005.

[22] LIN, X., YAN, Z., WANG, H., et al. "In-situ synthesis of NaY zeolite with coal-based kaolin", Journal of Natural Gas Chemestry, v.12, pp.63-70, 2003.

[23] FERNANDEZ-JIMENEZ, A., PALOMO, A., "Mid-infrared spectroscopic studies of alkali activated fly ash structure", Microporous Mesoporous, v.86, pp.207-14, 2005.

[24] PHAIR, J.W., VAN DEVENTER, J.S.J., "Effect of the silicate activator $\mathrm{pH}$ on the microstructural characteristics of waste-based geopolymers", International Journal of Mineral Processing, v.66, pp.121-43, 2002.

[25] LAZARER, A.N., Vibrational Spectra and Structure of silicates, Consultants Bureau, New York/London, 1972.

[26] NAKAMOTO, K. Infrared and Raman Spectra of Inorganic and Coordination Compounds, Wiley, Chichester, 1997.

[27] CRIADO, M., FERNANDEZ-JIMENEZ, A., PALOMO, A., "Alkali activation of fly ash: Effect of the $\mathrm{SiO}_{2} / \mathrm{Na}_{2} \mathrm{O}$ ratio Part I: FTIR study ", Microporous and Mesoporous Materials, v.106, pp.180-191, 2007.

[28] TAHRI, W., SAMET, B., PACHECO-TORGAL, F., et al., "Shrinkage and mechanical performance of geopolymeric mortars based on Tunisian clay", Chemestry and Materials Research v.4, No1, pp 6-11, 2013. 